\title{
The Guiding Role of Marxism on Internet Public Opinion
}

\author{
LiuWeiyang \\ Nanchang Institute of Science \&Technology,Nanchang 330108,China
}

\begin{abstract}
Keywords: Network public opinion;Monitoring; Marxism education;;Mathematical statistics analysis Abstract. The current Marxism education of college students in the context of network public opinion presents additional challenges, Marxism education should fully guide college students to strengthen the understanding of network public opinion, give full play to college network supervision system, Marxism education and the network public opinion is complementary, promote each other. Network public opinion can spread the Marxism education, Marxism education is helpful to promote the network public opinion toward the right path. This paper in view of the current to network public opinion of literature theory, construct the network public opinion monitoring of university Marxism education model, which can effectively guide the Marxism education workers. To strengthen the Marxism education and at the same time, correctly guide students toward the correct direction to grasp and use the network public opinion, to achieve self-development, self-improvement.
\end{abstract}

\section{Introduction}

The current rapid development of society and modern science technology, especially the rapid change of network technology, university students have gradually showed a strong influence on public opinion[1-3]. The current study of network public opinion is only limited to the theoretical, the quantitative analysis is less, and the concept of network public opinion is not clear, the theoretical study is greater than the empirical study, and pay more attention to the presentation analysis of the network public opinion, lack analysis on substantive characteristics of the network public opinion[5]. The paper combined with the network public opinion data, and the empirical analysis on the current situation of Marxism education of university students in the network public opinion, provide favorable basis, so as to better guide the universities to carry out the Marxism education on university students. Universities should pay strict attention to necessity and importance of network public opinion for the university students' Marxism education, should make a careful analysis of its forming factors, which is helpful to accurately grasp the characteristics of network public opinion, so that take more effective measures and methods to strengthen the Marxism education guidance, do their utmost to do Marxism education work under the network public opinion monitoring[6-7].

\section{The basic theory of network public opinion}

Network public opinion, expressed in a virtual network, given the multiple external stimuli are produced can be spread through the network, most of the Internet users will hold a kind of comprehensive cognition, thought and attitude which related to oneself or something they cared. Currently a large social groups are university students, the special group status affects not only the development of the country, also affects the progress of the society[8]. Therefore, we must value the university students' network public opinion situation, understanding the university students' Marxism education status. 
Network public opinion not only includes the subject and object, also need to have the source, body and carrier. The subject is the netizen, netizen in China mostly young people which have a relatively high level of education. The society has its own unique views and opinions. Secondly, the object, is the specific affairs spread on the network. Usually covered many of the stimulus information. Third, the source refers to the spatial and temporal factors. Only at a specific time and space range can cause the formation and change of network public opinion. The daily things are rarely cause great attention and concern[9]. Native is content, is based on the cognition, thought and attitude of people in the network spreading. The last is the carrier, through the extensive application of the network technology the network dissemination of ideas, now not only have podcast, micro-blog and various ways and means of communication.

\section{University students' Investigation and analysis based on network public opinion}

In universities, the network public opinion arouses public attention and concern, to keep track of university students' network public opinion dynamics, but also to effectively guide college students' online public opinion and its development trend[9]. The network public opinion are mainly embodied in the moral network, network application and network supervision etc..

This paper carry out a questionnaire in universities, each grade select a class as a research object, and make mathematical statistics analysis on the date, the expressions is:

This paper in Colleges and universities to carry out a questionnaire, each year to select a class as a research object, and the data were analyzed with mathematical statistics, expressions for the formula[10]:

$$
x_{i j}=\bar{x}+\left(\bar{x}_{i}-\bar{x}\right)+x_{i j}-x_{i}
$$

Observed value Average value $\hat{\mu}$, Treatment effect estimation $\hat{\tau}_{i}$, Surplus $\hat{e}_{i j}$, Overall mean vector for $\mathrm{P}[11]$

$$
\underset{p \times 1}{\mu}=\left(\begin{array}{l}
\mu_{1} \\
\mu_{2} \\
\cdots \\
\mu_{p}
\end{array}\right)
$$

Each component $\mu_{i}$ 's $\mathrm{p}=1-\alpha$ confidence interval[12]:

$$
\bar{x}_{i}-t_{n-1\left(\frac{\alpha}{2}\right)} \sqrt{\frac{s_{i i}}{n}} \leq \mu_{i} \leq \bar{x}_{i}+t_{n-1\left(\frac{\alpha}{2}\right)} \sqrt{\frac{s_{i i}}{n}} \ldots \ldots .
$$

$S_{\mathrm{ii}}$ refers to association matrix, while the $\mathrm{S}$ is expressed as the I variable variance. The above data, through the SAS statistical analysis software to output the findings can be get the result.

From table 1 and Figure 1,we can clearly get the empirical investigation of the fourth grade students' Marxism education. Various grades have different proportion of boys and girls for the Marxism education's awareness, especially in the second grade and the third grade when girls and boys all have a large proportion. The boys in the second grade accounted for the largest proportion of $30.83 \%$, female students in the third grade when the largest proportion is $33.2 \%$. This shows that, the freshman for the network 's attention is novelty, not pay much attention to the control of network public opinion. While in senior, they faced with more social pressure, the university students reflects a more sensible choice on network, can be more rational treat the network public opinion, can understand more adequately, think more comprehensive. 
Tab.1 The research object of the related statistical data

\begin{tabular}{|c|c|c|c|c|c|c|}
\hline \multicolumn{2}{|c|}{ Gender, Grade } & Grade 1 & Grade 2 & Grade 3 & Grade 4 & Total \\
\hline \multirow{2}{*}{ Boys } & Number & 150 & 209 & 191 & 128 & 678 \\
\cline { 2 - 7 } & Proportion(\%) & 22.12 & 30.83 & 28.17 & 18.88 & 71.44 \\
\hline \multirow{2}{*}{ Girls } & Number & 56 & 77 & 90 & 48 & 271 \\
\cline { 2 - 7 } & Proportion(\%) & 20.66 & 28.41 & 33.2 & 17.71 & 28.46 \\
\hline \multirow{2}{*}{ Total } & Number & 206 & 286 & 281 & 176 & 949 \\
\cline { 2 - 7 } & Proportion(\%) & 21.71 & 30.14 & 29.61 & 18.55 & 100.00 \\
\hline
\end{tabular}

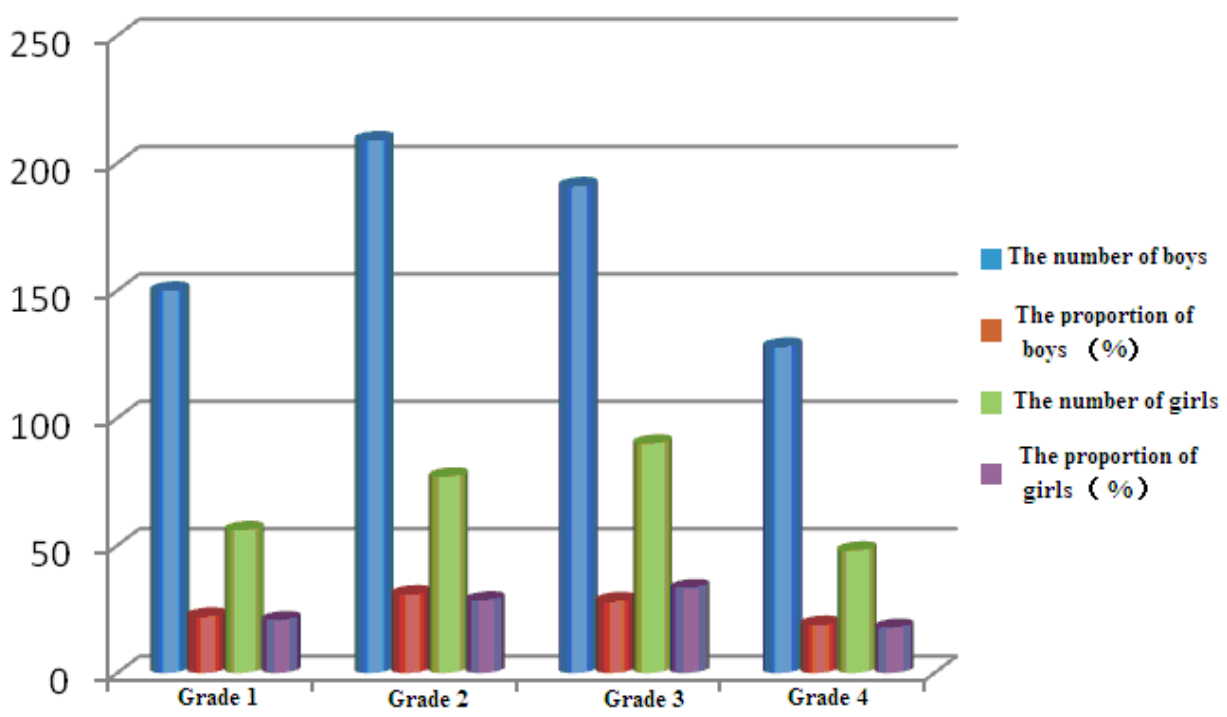

Fig 1 Empirical investigation on one to four grade students' Marxism education

Students not only beneficial to the network recreational activities, but also learning, shopping, dating, richen life through the network, as shown in Figure 2, the largest proportion is email, reaching $14.65 \%$; second is listening to music, watching TV and movies, accounted for $14.42 \%$; the third is learning, access to information, accounted for $11.56 \%$. And the last is the network game, accounted for $4.58 \%$, the students can realize the game only as a temporary entertainment activities, and not to give up learning. The use of network public opinion is still for the purpose of learning to enhance the self development. 


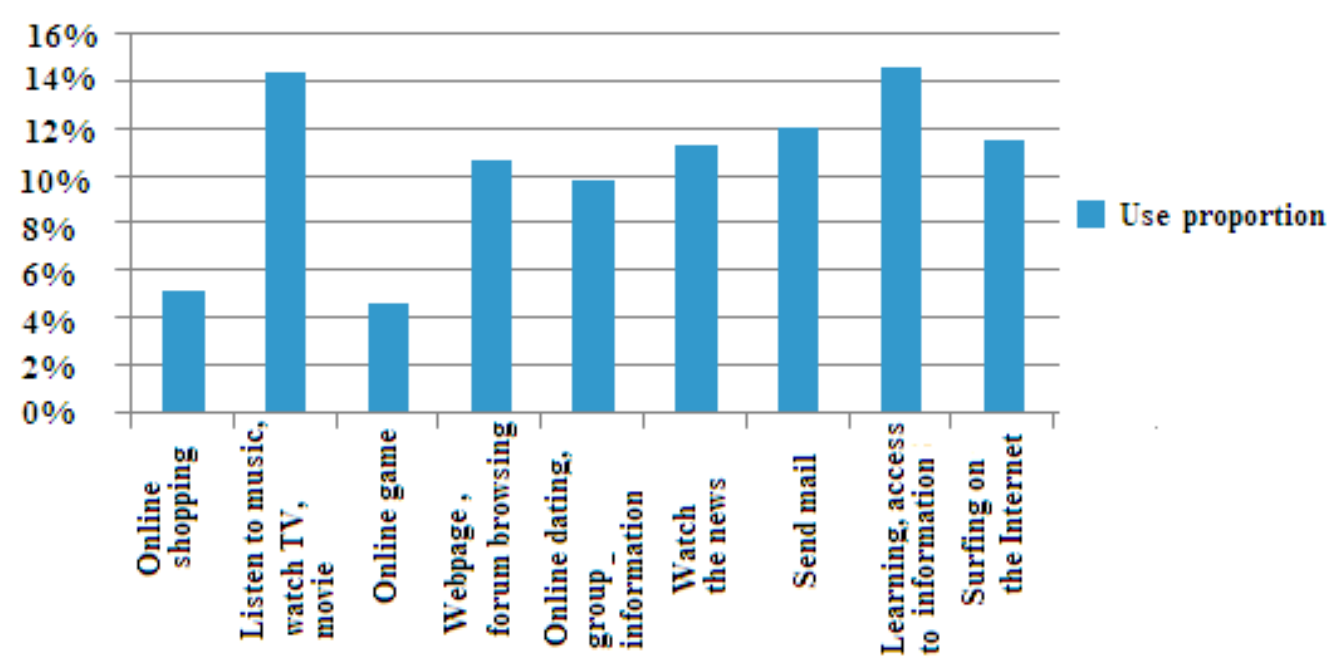

Fig 2 The comparison chart of students using the network

\section{Mode analysis on Marxism education network public opinion monitoring}

In order to realize the effective monitoring of network public opinion, it must do a good job of collection and auditing information and standardized management of network public opinion, the network public opinion for the university students' Marxism education mode is the Internet public opinion, such as the WEB data mining, the search engine and so on, the feedback was out of the question and situation and data through a certain the way and the method such as the online searching, questionnaire survey to collect processing, to reflect the network public opinion monitoring system of university students' Marxism education situation and the variable parameter index. At the same time to guide the Marxism education in universities, find out the deficiency, strengthen guiding, guide the students to make better use of network public opinion to strengthen Marxism education[13].

Marxism education network public opinion monitoring model is mainly composed of information resource collection, processing, review, published manage five parts, shown in Figure 3. Each part is the whole of organic union, both independent, and rely on each other, each part contains several level two module, are available through the network to effective link, according to the principle of the establishment of the distributed database model[14]. Collection of information resources not only relates to the distributed information but also realizes to the electronic information processing, audio video file of production and so on. Processing of information resource would require the use of collaborative online to carry out these resources arrangement, classification and processing, to achieve the data structure and information in order. Then according to the requirement of the information content of auditing. Then audit the information distributing section, to construct the corresponding database, data storage and dynamic query update and other functions. The last is the management of information resources, the information from a data base is content management, authorization limit distribution as well as the reading regulation[15]. 


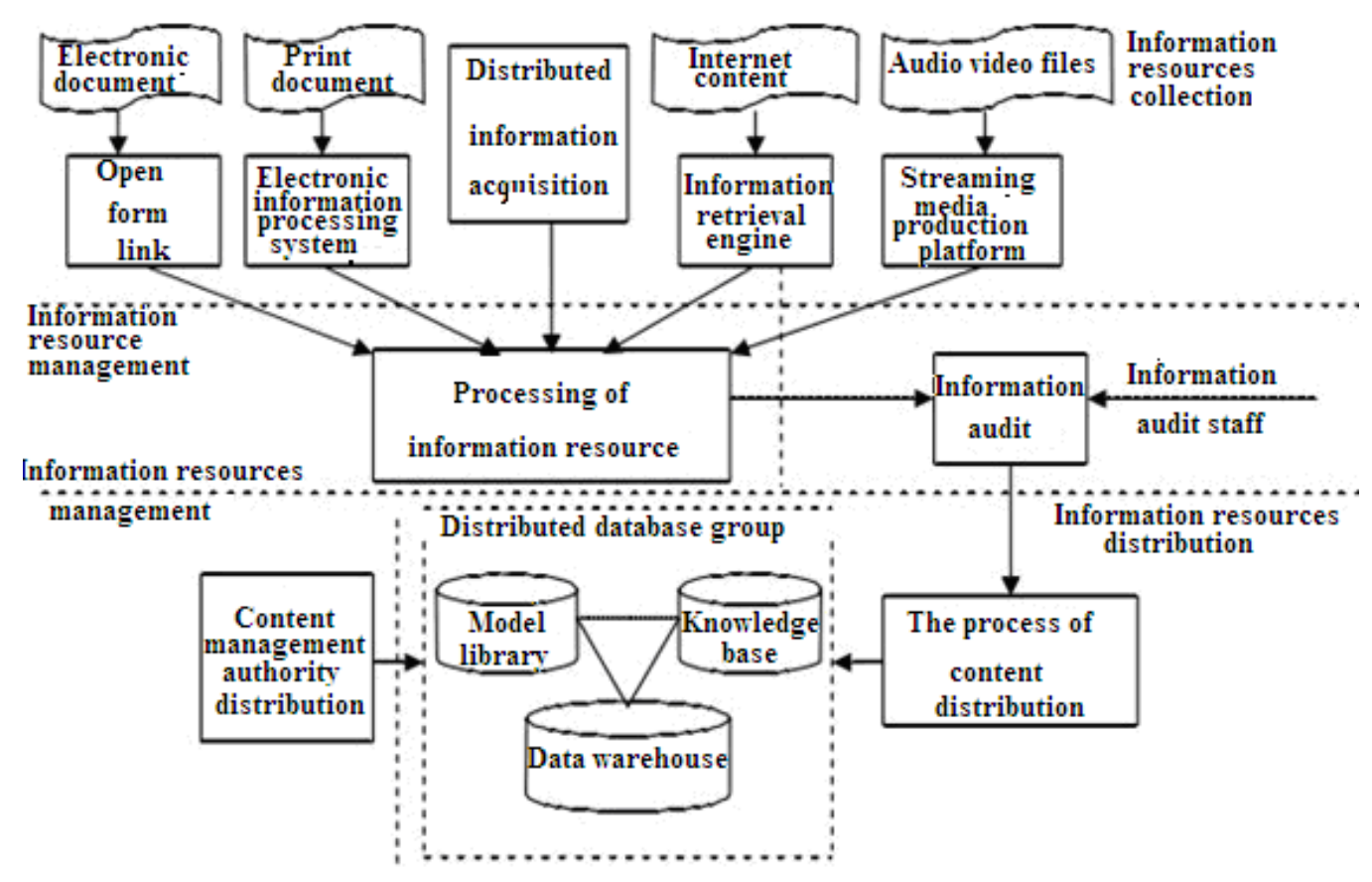

Fig 3 Monitoring mode of the university Marxismeducation on network public opinion

The information of network public opinion not only have strong timeliness but also widely distributed, so we must take the dynamic view of the development and changes of things, this paper establishes the Marxism education of university students in the network public opinion monitoring model, not only realizes dynamic grasp of university students' Marxism, but also can give full play to the role of network public opinion. The network public opinion resources can be fully utilized, in order to guide the Marxism education to effectively, play the role of network public opinion, achieve the modern technology integration, real-time, dynamic command to a variety of information, strengthening the promotion of university students' Marxism education.

\section{Conclusion}

The prevail of network in universities brings big impact for the current university students' Marxism education, also leads to network public opinion have a great influence on university students' thought, attitude. The current network public opinion has become a common concern of the society, also become the focus new areas university Marxism education. This artical serve the foundation literature literature of network public opinion as a starting point, doing actual research direct at the four grade students, to understand the current situation of Marxism education of university students, at the same time with mathematical statistics method SAS to statistical analysis, constructed a university students' Marxism education in the network public opinion monitoring model, in order to guide college Marxism education workers pay more attention to college students' Marxism dynamics. Strengthening the collection of information resources links, the effective use of information resources processing, audit functions, to achieve the effective information release, eventually achieve good Marxism education. 


\section{References}

[1] Qin Cheng. Faced with financial crisis: the employment is the people's Livelihood -- the return of migrant workers and college students employment network public opinion reports[J].Today's Massmedia,2009(2):23-26.

[2] Jiang Hongsheng. Present situation and guide of Internet public opinion in China [J].Guangxi Social Sciences,2009(1):33-36.

[3] Wang Wei.Innovation in new media era of public opinion management system[J].Journalism Lover: the second half ,2011(12):59-61.

[4] Zhao Yingsi, Liu Yun. BBS public opinion system data collecting method[J]. Telecommunications Information: communication network,2009(12):44-45.

[5] Wu Mingyou. Analysis on coping strategies of campus network public opinion [J].Information technology education in China: Basic Education,2010(12):66.

[6] Han Bing. Solution to network public opinion monitoring[J].Corporate Culture,2011(12):55-57.

[7] Si Jin.From the Internet public opinion formation characteristics on creating three-dimensional network monitoring mechanism[J].Netinfo security,2009(8):102-104.

[8] Li Shuchen,Liu Yun,Li Yong.Internet public opinion analysis of webpage information preprocessing scheme[J].Computer \& Telecommunication,2011(10):67-69.

[9] Zhang Xiaoli.Analysis of network public opinion guidance[J].News World,2009(11):39-41.

[10] Li Zide.The view of a harmonious society in the early warning of adverse public opinion on the Internet[J].Journal of China University of Petroleum(Edition of Social Sciences),2011, 24(4): 112-114.

[11] Liu Xiang.Network public opinion to government behavior influence research[D].Shanghai Jiao Tong University,2010.

[12] Qiu Jing,Liao Lejian.Internet public opinion and safety early warning technology of network culture[J].Netinfo security,2011(6):51-54.

[13] Xie Xiaozhuan.Problems of the net-mediated public opinion and construction of the mechanism of intelligence work[J].Journal of Fujian Public Safety College,2009,22(5):54-57

[14] Du Yuncheng, Wang Haiyang, Wang Hongjun.TRS network monitoring solution[J].Netinfo security,2012(6):56

[15] $\mathrm{Hu}$ Shengfang. Based on the netizens agree to form the network public opinion research[J].New West : the second half, 2011(7):54-57 